\title{
Early-life exposure to the Chinese famine of 1959-61 and risk of Hyperuricemia: results from the China health and retirement longitudinal study
}

Wenqiang Zhang and Rongsheng Luan*

\begin{abstract}
Background: Short-term starvation has been related to hyperuricemia. However, little is known about the long-term effect of early-life exposure to famine on hyperuricemia risk in adulthood.

Methods: The analysis included 2383 participants from the China Health and Retirement Longitudinal Study in 2015. Hyperuricemia was diagnosed as serum uric acid $\geq 7 \mathrm{mg} / \mathrm{dL}$ in men and serum uric acid $\geq 6 \mathrm{mg} / \mathrm{dL}$ in women. Famine exposure subgroups were defined as unexposed (born between October 1, 1962, and September 30, 1964), fetalexposed (born between October 1, 1959, and September 30, 1961), and early-childhood exposed (born between October 1, 1956, and September 1, 1958). The association between early-life famine exposure and hyperuricemia risk was assessed using multivariate logistic regression.

Results: The prevalence of hyperuricemia in the unexposed, fetal-exposed, and early-childhood exposed participants was $10.7,14.1,11.1 \%$, respectively. Compared with unexposed and early-childhood exposed participants combined as an age-balanced control, fetal-exposed participants showed an increased risk of hyperuricemia in adulthood (OR=1.41; 95\% Cl: 1.06-1.88), after adjusting for gender, marital status, famine severity, residence, smoking, drinking, BMI, hypertension, and diabetes. The famine effect on hyperuricemia was accentuated by overweight or obesity ( $P$ for interaction $=0.042$ ). Compared with unexposed and $\mathrm{BMl}<24 \mathrm{~kg} / \mathrm{m}^{2}$ participants, the $O R(95 \% \mathrm{Cl})$ of hyperuricemia was 3.66 (2.13-6.30) for fetal-exposed and overweight/obesity participants. However, combined unexposed and earlychildhood exposed participants as an age-balanced control, the interaction of famine exposure and BMI was not statistically significant ( $P$ for interaction $=0.054$ ).
\end{abstract}

Conclusion: Famine exposure in the fetal stage was associated with an increased risk of hyperuricemia in adulthood.

Keywords: Starvation, Hyperuricemia, Prenatal exposure delayed effects

\section{Background}

Serum uric acid (SUA) is a natural product of purine metabolism. The overproduction or underexcretion of uric acid can result in hyperuricemia [1,2]. Recently, the prevalence of hyperuricemia has been increasing throughout the world [3-5]. A national cross-sectional survey in Chinese adults showed the prevalence of hyperuricemia was $8.4 \%$, approximately 92.9 million adults with hyperuricemia [6].

\footnotetext{
*Correspondence: luan_rs@scu.edu.cn

West China School of Public Health and West China Fourth Hospital, Sichuan University, No. 16, Section 3, Ren Min Nan Road, Chengdu 610041, Sichuan,
} China

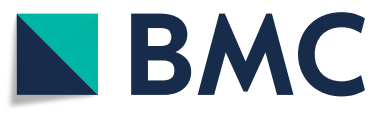

(c) The Author(s). 2020 Open Access This article is distributed under the terms of the Creative Commons Attribution 4.0 International License (http://creativecommons.org/licenses/by/4.0/), which permits unrestricted use, distribution, and reproduction in any medium, provided you give appropriate credit to the original author(s) and the source, provide a link to the Creative Commons license, and indicate if changes were made. The Creative Commons Public Domain Dedication waiver (http://creativecommons.org/publicdomain/zero/1.0/) applies to the data made available in this article, unless otherwise stated.

Furthermore, hyperuricemia is the dominant risk factor for gout and might cause worse outcomes in cardiovascular disease and chronic kidney disease [7-9].

Both non-genetic and inherited genetic risk factors can contribute to hyperuricemia [2]. Previous epidemiological studies indicated hyperuricemia was associated with age, gender, obesity, drinking, smoking, dietary, genes [2, 3, 10-14]. In clinical studies, short-term starvation has been related to hyperuricemia [15-17]. However, epidemiological evidence for the long-term effect of early-life famine exposure on hyperuricemia in later life was still limited. 
The Chinese Great Famine in 1959-61 lasted for a relatively prolonged period, which could provide us with a natural experiment to investigate the association between famine in early life and hyperuricemia risk. In the present study, we used the data from the China Health and Retirement Longitudinal Study in 2015 to examine whether early-life exposure to the Chinese famine of 1959-61 increased the risk of hyperuricemia in later life.

\section{Methods}

\section{Participants}

The China Health and Retirement Longitudinal Study (CHARLS) is a nationally representative longitudinal survey of persons aged 45 years or older and their spouses, including household questionnaire, clinical measurements, and blood biomarkers [18]. For the current study, 2482 participants were enrolled into three famine exposure subgroups from 14,320 venous blood samples in the 2015 Wave of CHARLS. We dropped 99 participants who had missing data or outliners (Additional file 1: Table S1). As a result, the analysis included 2383 participants (Fig. 1).

\section{Assessment of famine exposure and severity}

We categorized participants by actual birthdate into three famine exposure subgroups:

unexposed (born between October 1, 1962, and September 30, 1964), fetal-exposed (born between October 1, 1959, and September 30, 1961), and early-childhood exposed (born between October 1, 1956, and September 1, 1958). To avoid the age-related biases [19], we combined unexposed and early-childhood exposed subgroup as an age-balanced control.

The severity of Chinese famine varied remarkably across regions and time [19]. As shown in previous studies [20-23], provincial excess mortality in 1956-62 was computed as an indicator of famine severity, and excess mortality of $50 \%$ was used to classify provinces into severely affected and less severely affected areas.

\section{Diagnosis of hyperuricemia}

As widely accepted in previous studies [6, 24-26], hyperuricemia was defined as $\mathrm{SUA} \geq 7 \mathrm{mg} / \mathrm{dL}$ for men or $\mathrm{SUA} \geq 6 \mathrm{mg} / \mathrm{dL}$ for women.

\section{Covariates}

Hypertension was defined as a self-report of doctor diagnosis or systolic blood pressure $\geq 140 \mathrm{mmHg}$ or diastolic blood pressure $\geq 90 \mathrm{mmHg}$. Diabetes was defined as a self-report of doctor diagnosis or fasting blood glucose $\geq 126 \mathrm{mg} / \mathrm{dL}$ or $\mathrm{HbA} 1 \mathrm{c} \geq 6.5 \%$. Gender (male $=1$ and female $=0$ ), marital status (if married and living with spouse $=1$, and 0 otherwise), smoking (former or current $=1$, and never $=0$ ), drinking (former or current = 1 , and never $=0$ ), residence (urban $=1$ and rural $=0$ ), hypertension (yes $=1$ and no $=0$ ), diabetes (yes $=1$ and no $=0)$ were coded as dichotomous variables. The body mass index (BMI) was calculated as weight in kilograms divided into height in meters squared $\left(\mathrm{kg} / \mathrm{m}^{2}\right)$. Based on the criteria recommendation for Chinese adult [27], overweight or obesity were defined as BMI $\geq 24.0 \mathrm{~kg} / \mathrm{m}^{2}$.

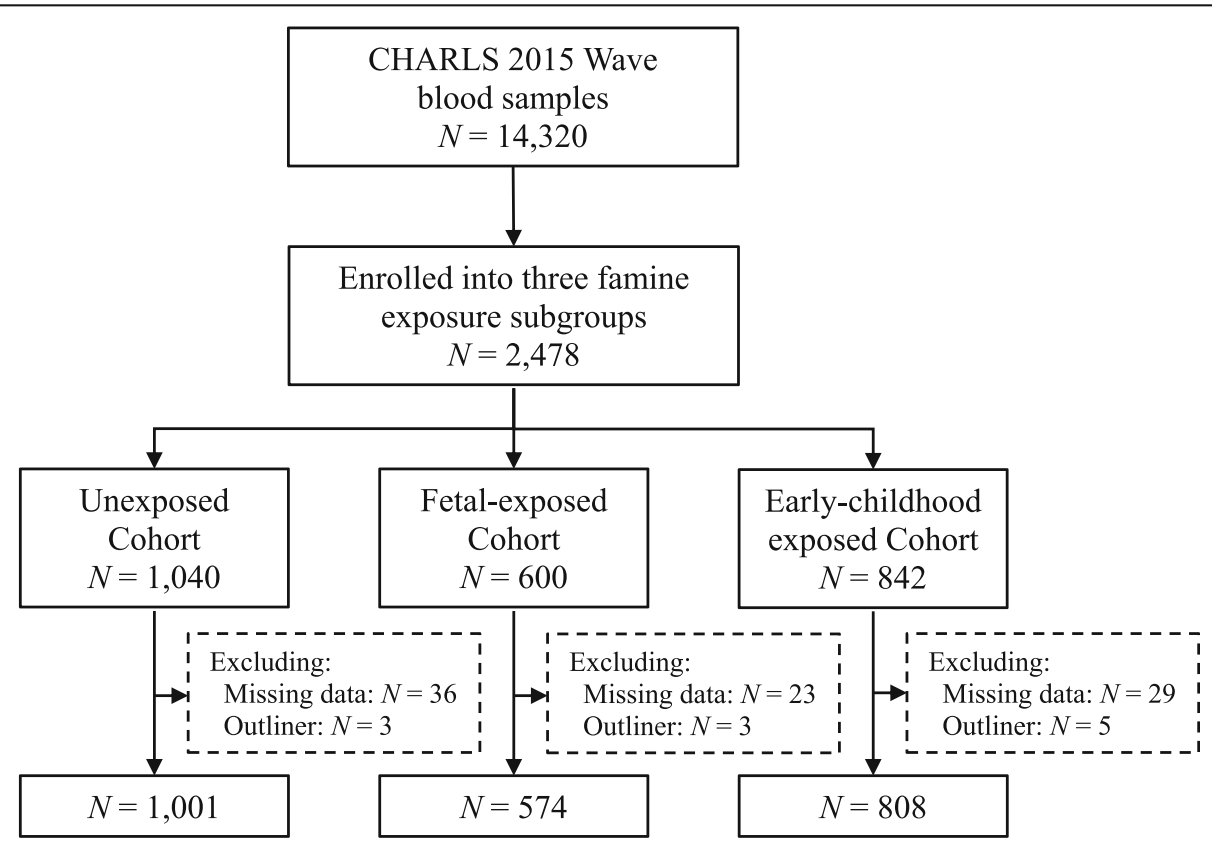

Fig. 1 Flowchart on the sample selection and exclusion 


\section{Statistical analysis}

Pearson's Chi-Square test was used to detect the difference of categorical variables between two famineexposed subgroups and the unexposed. The Bonferroni corrections were used to conduct post-hoc comparisons with the unexposed. We calculated odds ratios (ORs) with 95\% confidence intervals (CIs) for risk of hyperuricemia by unconditional logistic regression, progressively adjusted for gender, marital status, famine severity, residence, smoking, drinking, BMI, hypertension, and diabetes. We assessed the multiplicative interaction of famine exposure, gender, residence, famine severity, BMI by the likelihood ratio test. A two-tailed $P<0.05$ was considered as statistically significant. All statistical analyses were performed using Statistical Product and Service Solutions (SPSS, version 23.0).

\section{Results}

Table 1 presents the characteristics of all participants according to the famine exposure in early life. The sample size of the unexposed, fetal-exposed, and early-childhood exposed subgroup were 1001, 574, 808, respectively. All three famine exposure subgroups resembled each other in terms of gender compositions (about 53-56\% female), marital status (roughly $88-90 \%$ married and living with spouse), and residence (over $72 \%$ lived in rural). Additionally, more than $50 \%$ of all participants were overweight or obesity. The differences of smoking and hypertension between three famine exposure subgroups were statistically significant $\left(X^{2}=6.345, P=0.042 ; X^{2}=13.536, P<0.001\right)$. Compared with the unexposed participants, the prevalence of smoking and hypertension for the earlychildhood exposed was higher $(P<0.025)$. The prevalence of hyperuricemia among the unexposed, fetal-exposed, and early-childhood exposed subgroup was 10.7, 14.1, $11.1 \%$, respectively.

The associations between famine exposure and the risk of hyperuricemia are shown in Table 2. Compared with the unexposed participants, the unadjusted $O R(95 \% C I)$ of hyperuricemia was 1.37 (1.01-1.87) for fetal-exposed participants. After adjustment for gender, marital status, famine severity, residence, smoking, drinking, BMI, hypertension, and diabetes, the $O R$ of hyperuricemia for fetal-exposed participants was statistically significant $(\mathrm{OR}=1.44 ; \quad 95 \% C I$ : 1.05-1.98). Furthermore, even

Table 1 Characteristics of participants according to the Chinese famine exposure

\begin{tabular}{|c|c|c|c|}
\hline & Unexposed & Fetal-exposed & Early-childhood exposed \\
\hline$N(\%)$ & 1001 & 574 & 808 \\
\hline \multicolumn{4}{|l|}{ Birthdate } \\
\hline From Oct 1, year & 1962 & 1959 & 1956 \\
\hline To Sep 30, year & 1964 & 1961 & 1958 \\
\hline \multicolumn{4}{|l|}{ Gender, $n(\%)$} \\
\hline Male & $441(44.1)$ & $256(44.6)$ & $380(47.0)$ \\
\hline Female & $560(55.9)$ & $318(55.4)$ & $428(53.0)$ \\
\hline \multicolumn{4}{|l|}{ Marital, n (\%) } \\
\hline Married and living with spouse & $902(90.1)$ & $508(88.5)$ & $713(88.2)$ \\
\hline Otherwise & $99(9.9)$ & $66(11.5)$ & $95(11.8)$ \\
\hline \multicolumn{4}{|l|}{ Residence, $n$ (\%) } \\
\hline Urban & $274(27.4)$ & $142(24.7)$ & $208(25.7)$ \\
\hline Rural & $727(72.6)$ & $432(75.3)$ & $600(74.3)$ \\
\hline \multicolumn{4}{|l|}{ Famine severity, $n(\%)$} \\
\hline Severely & $631(63.0)$ & $338(58.9)$ & $493(61.0)$ \\
\hline Less severely & $370(37.0)$ & $236(41.1)$ & $315(39.0)$ \\
\hline Smoking, n (\%) & $363(36.3)$ & $234(40.8)$ & $337(41.7) \dagger$ \\
\hline Drinking, $n(\%)$ & $378(37.8)$ & $218(38.0)$ & $292(36.1)$ \\
\hline Overweight/obesity, n (\%) & $541(54.0)$ & $292(50.9)$ & $410(50.7)$ \\
\hline Hypertension, $n$ (\%) & $288(28.8)$ & $191(33.3)$ & 298 (36.9)‡ \\
\hline Diabetes, $n(\%)$ & $135(13.5)$ & $92(16.0)$ & $136(16.8)$ \\
\hline Hyperuricemia, n (\%) & $107(10.7)$ & $81(14.1)$ & $90(11.1)$ \\
\hline
\end{tabular}

†Between the groups, $X^{2}=6.345, P=0.042$. Compared with the unexposed, $P<0.025$ (Bonferroni correction)

$\neq$ Between the groups, $X^{2}=13.536, P<0.001$. Compared with the unexposed, $P<0.025$ (Bonferroni correction) 
Table 2 Association of famine exposure in early life with hyperuricemia

\begin{tabular}{llll}
\hline & Unexposed & Fetal-exposed & Early-childhood exposed \\
\hline Unadjusted & & & \\
$\quad$ OR $(95 \%$ Cl) & 1.00 & $1.37(1.01-1.87)$ & $1.05(0.78-1.41)$ \\
Adjusted & & & \\
OR (95\% Cl) & 1.00 & $1.44(1.05-1.98)$ & $1.04(0.77-1.42)$ \\
\hline
\end{tabular}

Abbreviations: $O R$ odd ratio, $\mathrm{Cl}$ confidence interval

compared with unexposed and early-childhood exposed participants combined, an age-balanced control, and adjusted potential confounders, the famine exposure in the fetal stage was associated with an increased risk of hyperuricemia (Additional file 1: Table S2). However, consistent results were not observed in the earlychildhood exposed participants, when compared with unexposed participants.

As shown in Table 3, a multiplicative interaction was observed between famine exposure and BMI on hyperuricemia $\left(P_{\text {interaction }}=0.042\right)$. Compared with unexposed and $\mathrm{BMI}<24 \mathrm{~kg} / \mathrm{m}^{2}$ participants, the $O R(95 \% C I)$ of hyperuricemia was 3.66 (2.13-6.30) for fetal-exposed and overweight/obesity participants after adjusted other covariates. When combined unexposed and early-childhood exposed participants as an age-balanced control, the interaction of famine exposure and BMI was not statistically significant $(P$ interaction $=0.054$, Additional file 1: Table S3). Additionally, there was no statistical interaction between gender, famine severity, residence, and famine exposure on hyperuricemia $\left(P_{\text {interaction }}>0.05\right)$.

\section{Discussion}

In this study using data from the China Health and Retirement Longitudinal Survey, fetal famine exposure was associated with an increased risk of hyperuricemia in adulthood. The famine effect on hyperuricemia was accentuated by overweight/obesity. Compared with unexposed and $\mathrm{BMI}<24 \mathrm{~kg} / \mathrm{m}^{2}$ participants, those who were exposed to famine in the fetal stage and overweight/ obesity had more than three times higher risk of hyperuricemia.

Previous studies have shown serum uric acid concentration would increase during starvation [15-17]. Furthermore, our study for the first time found that the experience of famine in the fetal stage was associated with hyperuricemia in later life. Accumulating evidence suggests that intrauterine malnutrition is associated with low fetal birth weight and low renal nephron numbers at all ages [28, 29]. The age-induced renal changes and structural changes may occur earlier in life because of intrauterine malnutrition, which means the occurrence of glomerular filtration rate decline is earlier [30]. The alterations in renal function may cause underexcretion of uric acid, which is likely to contribute to the development of hyperuricemia [16, 31, 32]. Further studies should be conducted to assess the effects of maladaptive adjustment to genes expression and renal dysfunction on hyperuricemia. In addition, the association between fetal famine exposure and hyperuricemia in adulthood did not change substantially after adjustment for overweight/obesity and other covariates, suggesting that overweight/obesity might not be a mediator for the association.

Table 3 Multivariable-adjusted ORs (95\%Cl) for the association of gender, BMI, and famine exposure in early life with hyperuricemia

\begin{tabular}{|c|c|c|c|c|}
\hline & Unexposed & Fetal-exposed & Early-childhood exposed & $P$ interaction \\
\hline Gender $^{a}$ & & & & 0.374 \\
\hline Female & 1.00 & $1.29(0.80-2.06)$ & $1.96(1.17-3.28)$ & \\
\hline Male & $1.56(0.95-2.58)$ & $2.46(1.43-4.26)$ & $0.81(0.50-1.30)$ & \\
\hline Famine severity ${ }^{\mathrm{b}}$ & & & & 0.351 \\
\hline Less severity & 1.00 & $1.31(0.77-2.22)$ & $1.27(0.77-2.08)$ & \\
\hline Severity & $1.20(0.78-1.85)$ & $1.85(1.16-2.96)$ & $1.11(0.70-1.76)$ & \\
\hline Residence $^{c}$ & & & & 0.548 \\
\hline Rural & 1.00 & $1.54(1.05-2.25)$ & $1.16(0.81-1.67)$ & \\
\hline Urban & $1.29(0.84-2.00)$ & $1.61(0.95-2.73)$ & $1.03(0.62-1.73)$ & \\
\hline $\mathrm{BMl}, \mathrm{kg} / \mathrm{m}^{2 \mathrm{~d}}$ & & & & 0.042 \\
\hline$<24$ & 1.00 & $2.58(1.49-4.53)$ & $1.58(0.89-2.78)$ & \\
\hline$\geq 24$ & $3.39(2.06-5.57)$ & $3.66(2.13-6.30)$ & $3.00(1.78-5.06)$ & \\
\hline
\end{tabular}

Abbreviations: $\mathrm{OR}$ odds ratio, $\mathrm{Cl}$ confidence interval, BMI body mass index

a adjust marital status, famine severity, residence, smoking, drinking, BMI, hypertension, and diabetes

b adjust gender, marital status, residence, smoking, drinking, BMI, hypertension, and diabetes

c adjust gender, marital status, famine severity, smoking, drinking, BMl, hypertension, and diabetes

$\mathrm{d}$ adjust gender, marital status, famine severity, residence, smoking, drinking, hypertension, and diabetes 
Our findings, consistent with previous studies [15, 33], indicated famine exposure in early life interacted with overweight/obesity during adulthood to influence hyperuricemia risk. Obesity has been linked to insulin resistance, which can facilitate the reabsorption of uric acid by augmenting the renal tubular sodium-hydrogen exchanger [34-36]. Additionally, impaired uric acid clearance is likely the main cause of hyperuricemia in obesity subjects because of the effect of hyperinsulinemia secondary to insulin resistance [34, 37]. As the thrifty phenotype hypothesis proposed, the occurrence of pathological changes following poor nutrition in early life may be dependent on the superimposition of risk factors in later life [38].

Consistent with some studies [20, 23, 39], we did not find any larger famine effects among adults born in severely affected versus less severely affected areas. This result may be explained by a great variation of famine severity in the county-level mortality [19], which caused the misclassification of famine severity. Further studies should be conducted that collect historical demographic records at the local level and find a more reliable indicator to better distinguish famine severity.

Additionally, we observed $52.5 \%$ of all participants aged $50-59$ years in 2015 and $46.9 \%$ of men were overweight and obesity, which was higher than men aged $15-49$ years $(36.4 \%)$ in 2014 [40]. Thus, we might speculate whether age or famine effects could increase the prevalence of overweight and obesity. Although a previous study indicated the association between the risk of overweight, obesity and exposure to famine in early life in women aged 54-56 years but not in men [39], more detailed evidence and prospective cohorts are needed to confirm the risk of health caused by famine exposure in early life.

Several limitations of this study should be noted. First, individual famine exposure records were absent. The timing and severity of the Chinese famine varied greatly across regions. We used participant's birthdate to distinguish famine exposure and computed excess mortality at the provincial level to measure famine severity. The misclassification bias was inevitable but should be nondifferential. To minimize potential misclassification, we excluded these participants born in the junction between three famine exposure subgroups. Second, medication information that may affect serum uric acid concentrations was not considered in the definition of hyperuricemia. Third, personal dietary information and family history of hyperuricemia was not available, which may be related to hyperuricemia. In addition, although the age-balanced control was used to avoid the age-related biases, the difference of age between the age-balanced control and fetal-exposed group still exists. Despite these limitations, this study has been among the first to investigate the long-term effects of early-life exposure to famine on hyperuricemia in Chinese adults.

\section{Conclusions}

Famine exposure in the fetal stage was associated with an increased risk of hyperuricemia in adulthood. And the famine exposure effect on hyperuricemia was accentuated by overweight/obesity.

\section{Supplementary information}

Supplementary information accompanies this paper at https://doi.org/10. 1186/s12889-019-8017-1.

Additional file 1: Table S1. Distributions of missing data and outliners among three famine exposure subgroups. Table S2. Association of famine exposure in early life with hyperuricemia. Table S3. Multivariableadjusted ORs $(95 \% C l)$ for the association of BMl, and famine exposure in early life with hyperuricemia.

\section{Abbreviations}

BMI: Body mass index; CHARLS: China Health and Retirement Longitudinal Study; Cl: Confidence interval; HbA1c: Glycated hemoglobin; OR: Odds ratio; SUA: Serum uric acid

\section{Acknowledgements}

The authors are grateful to the China Health and Retirement Longitudinal Study (CHARLS) team for providing data.

\section{Authors' contributions}

ZW conceived and designed the study, analysed the data and drafted the manuscript. LR advised on the interpretation of the results and manuscript revision and approved the final version of the manuscript. All authors reviewed and approved the final manuscript.

\section{Funding}

No funding was received.

\section{Availability of data and materials}

The datasets are available in the website http://charls.pku.edu.cn/en

Ethics approval and consent to participate

This study used public data from CHARLS to analyse. The blood-based biomarker sample collection study was granted by the ethical review committee (IRB) of Peking University (IRB 00001052-11014). Written informed consent was obtained from all participants.

Consent for publication

Not applicable.

\section{Competing interests}

The authors declare that they have no competing interests.

Received: 16 September 2019 Accepted: 28 November 2019 Published online: 06 January 2020

References

1. Ichida K, Matsuo H, Takada T, Nakayama A, Murakami K, Shimizu T, Yamanashi Y, Kasuga H, Nakashima H, Nakamura T, et al. Decreased extrarenal urate excretion is a common cause of hyperuricemia. Nat Commun. 2012;3:764.

2. Dalbeth N, Merriman TR, Stamp LK. Gout. Lancet. 2016;388(10055):2039-52.

3. Smith $E$, March L. Global prevalence of Hyperuricemia: a systematic review of population-based epidemiological studies. Arthritis Rheumatol. 2015;67:2690-2.

4. Zhu Y, Pandya BJ, Choi HK. Prevalence of gout and hyperuricemia in the US general population: the National Health and nutrition examination survey 2007-2008. Arthritis Rheum. 2011;63(10):3136-41. 
5. Trifiro G, Morabito P, Cavagna L, Ferrajolo C, Pecchioli S, Simonetti M, Bianchini E, Medea G, Cricelli C, Caputi AP, et al. Epidemiology of gout and hyperuricaemia in Italy during the years 2005-2009: a nationwide population-based study. Ann Rheum Dis. 2013;72(5):694-700.

6. Liu H, Zhang XM, Wang YL, Liu BC. Prevalence of hyperuricemia among Chinese adults: a national cross-sectional survey using multistage, stratified sampling. J Nephrol. 2014;27(6):653-8.

7. Testa A, Mallamaci F, Spoto B, Pisano A, Sanguedolce MC, Tripepi G, Leonardis D, Zoccali C. Association of a polymorphism in a gene encoding a urate transporter with CKD progression. Clin J Am Soc Nephrol. 2014;9(6):1059-65.

8. Mallamaci F, Testa A, Leonardis D, Tripepi R, Pisano A, Spoto B, Sanguedolce MC, Parlongo RM, Tripepi G, Zoccali C. A genetic marker of uric acid level, carotid atherosclerosis, and arterial stiffness: a family-based study. Am J Kidney Dis. 2015;65(2):294-302.

9. Kleber ME, Delgado G, Grammer TB, Silbernagel G, Huang J, Kramer BK, Ritz E, Marz W. Uric acid and cardiovascular events: a Mendelian randomization study. J Am Soc Nephrol. 2015;26(11):2831-8.

10. Yu S, Yang H, Guo X, Zhang X, Zhou Y, Ou Q, Zheng L, Sun Y. Prevalence of hyperuricemia and its correlates in rural northeast Chinese population: from lifestyle risk factors to metabolic comorbidities. Clin Rheumatol. 2016;35(5):1207-15.

11. Cui L, Meng L, Wang G, Yuan X, Li Z, Mu R, Wu S. Prevalence and risk factors of hyperuricemia: results of the Kailuan cohort study. Mod Rheumatol. 2017;27(6):1066-71.

12. Ali N, Perveen R, Rahman S, Mahmood S, Rahman S, Islam S, Haque T, Sumon AH, Kathak RR, Molla NH, et al. Prevalence of hyperuricemia and the relationship between serum uric acid and obesity: a study on Bangladeshi adults. PLoS One. 2018;13(11):e0206850

13. Lee MF, Liou TH, Wang W, Pan WH, Lee WJ, Hsu CT, Wu SF, Chen HH. Gender, body mass index, and PPARgamma polymorphism are good indicators in hyperuricemia prediction for Han Chinese. Genet Test Mol Biomarkers. 2013;17(1):40-6.

14. Shiraishi $\mathrm{H}$, Une $\mathrm{H}$. The effect of the interaction between obesity and drinking on hyperuricemia in Japanese male office workers. J Epidemiol. 2009:19(1):12-6.

15. Alderman MH, Davis RP. Hyperuricemia in starvation. P Soc Exp Biol Med. 1965;118(3):790-2.

16. Lennox WG. Increase of uric acid in the blood during prolonged starvation. J Am Med Assoc. 1924;82:602-4.

17. Lloydmostyn RH, Lord PS, Glover R, West C, Gilliland IC. Uric acid metabolism in starvation. Ann Rheum Dis. 1970;29(5):553-5.

18. Zhao Y, Hu Y, Smith JP, Strauss J, Yang G. Cohort profile: the China health and retirement longitudinal study (CHARLS). Int J Epidemiol. 2014;43(1):61-8.

19. Li C, Lumey LH. Exposure to the Chinese famine of 1959-61 in early life and long-term health conditions: a systematic review and meta-analysis. Int J Epidemiol. 2017;46(4):1157-70.

20. Wang Z, Li C, Yang Z, Ma J, Zou Z. Fetal and infant exposure to severe Chinese famine increases the risk of adult dyslipidemia: results from the China health and retirement longitudinal study. BMC Public Health. 2017; 17(1):488.

21. Wang Z, Li C, Yang Z, Zou Z, Ma J. Infant exposure to Chinese famine increased the risk of hypertension in adulthood: results from the China health and retirement longitudinal study. BMC Public Health. 2016;16:435.

22. Luo ZH, Mu R, Zhang XB. Famine and overweight in China. Rev Agr Econ. 2006;28(3):296-304.

23. Wang Z, Zou Z, Yang Z, Dong Y, Song J, Dong B, Ma J, Arnold L. The association between fetal-stage exposure to the China famine and risk of diabetes mellitus in adulthood: results from the China health and retirement longitudinal study. BMC Public Health. 2018;18(1):1205.

24. Wu J, Qiu L, Cheng XQ, Xu T, Wu W, Zeng XJ, Ye YC, Guo XZ, Cheng Q, Liu $\mathrm{Q}$, et al. Hyperuricemia and clustering of cardiovascular risk factors in the Chinese adult population. Sci Rep. 2017;7(1):5456

25. Zhang Y, Wei F, Chen C, Cai C, Zhang K, Sun N, Tian J, Shi W, Zhang M, Zang $Y$, et al. Higher triglyceride level predicts hyperuricemia: a prospective study of 6-year follow-up. J Clin Lipidol. 2018;12(1):185-92.

26. Kuwabara M, Niwa K, Hisatome I, Nakagawa T, Roncal-Jimenez CA, Andres-Hernando A, Bjornstad P, Jensen T, Sato Y, Milagres T, et al. Asymptomatic Hyperuricemia without comorbidities predicts Cardiometabolic diseases: five-year Japanese cohort study. Hypertension. 2017;69(6):1036-44
27. Chen C, Lu FC. Department of Disease Control Ministry of Health PRC. The guidelines for prevention and control of overweight and obesity in Chinese adults. Biomed Environ Sci. 2004;17(Suppl):1-36.

28. Mesquita FF, Gontijo JA, Boer PA. Maternal undernutrition and the offspring kidney: from fetal to adult life. Braz J Med Biol Res. 2010;43(11):1010-8.

29. Pham TD, MacLennan NK, Chiu CT, Laksana GS, Hsu JL, Lane RH. Uteroplacental insufficiency increases apoptosis and alters p53 gene methylation in the full-term IUGR rat kidney. Am J Physiol Regul Integr Comp Physiol. 2003;285(5):R962-70.

30. Franco M. Intrauterine undernutrition - renal and vascular origin of hypertension. Cardiovasc Res. 2003;60(2):228-34.

31. Murphy R, Shipman KH. Hyperuricemia during Total fasting: renal factors. Arch Intern Med. 1963;112:954-9.

32. Lennox WG. A study of the retention of uric acid during starvation. J Biol Chem. 1925;66:521-72.

33. Drenick EJ. Hyperuricemia, acute gout, renal insufficiency and urate nephrolithiasis due to starvation. Arthritis Rheum. 1965;8:988-97.

34. Quinones Galvan A, Natali A, Baldi S, Frascerra S, Sanna G, Ciociaro D, Ferrannini E. Effect of insulin on uric acid excretion in humans. Am J Phys. 1995;268(1 Pt 1):E1-5.

35. Ter Maaten JC, Voorburg A, Heine RJ, Ter Wee PM, Donker AJ, Gans RO. Renal handling of urate and sodium during acute physiological hyperinsulinaemia in healthy subjects. Clin Sci (Lond). 1997;92(1):51-8.

36. Lim SM, Choi DP, Rhee Y, Kim HC. Association between obesity indices and insulin resistance among healthy Korean adolescents: the JS high school study. PLoS One. 2015;10(5):e0125238.

37. Yamashita S, Matsuzawa Y, Tokunaga K, Fujioka S, Tarui S. Studies on the impaired metabolism of uric acid in obese subjects: marked reduction of renal urate excretion and its improvement by a low-calorie diet. Int J Obes. 1986;10(4):255-64.

38. Hales CN, Barker DJ. The thrifty phenotype hypothesis. Br Med Bull. 2001;60:5-20.

39. Chang $X$, Song $P$, Wang $M, A n L$. The risks of overweight, obesity and abdominal obesity in middle age after exposure to famine in early life: evidence from the China's 1959-1961 famine. J Nutr Health Aging. 2018; 22(10):1198-204.

40. He Y, Pan A, Wang Y, Yang Y, Xu J, Zhang Y, Liu D, Wang Q, Shen H, Zhang $Y$, et al. Prevalence of overweight and obesity in 15.8 million men aged 1549 years in rural China from 2010 to 2014. Sci Rep. 2017;7(1):5012.

\section{Publisher's Note}

Springer Nature remains neutral with regard to jurisdictional claims in published maps and institutional affiliations.

Ready to submit your research? Choose BMC and benefit from:

- fast, convenient online submission

- thorough peer review by experienced researchers in your field

- rapid publication on acceptance

- support for research data, including large and complex data types

- gold Open Access which fosters wider collaboration and increased citations

- maximum visibility for your research: over $100 \mathrm{M}$ website views per year

At $\mathrm{BMC}$, research is always in progress.

Learn more biomedcentral.com/submissions 